\title{
The Attitude towards Preventive Measures and Knowledge of COVID-19 Inpatients with Severe Mental Illness in Economically Underdeveloped Areas of China
}

\author{
Ju-Hong Zhu ${ }^{1} \cdot$ Wen $\mathrm{Li}^{2}$ (D) Xiao-Ning Huo ${ }^{3} \cdot$ Hong-Min Jin ${ }^{4} \cdot$ Chun-Hu Zhang ${ }^{5} \cdot$ \\ Jin-De Yun ${ }^{6} \cdot$ Li-Guo Gao $^{7} \cdot$ Teris Cheung $^{8} \cdot$ Brian J. Hall $^{9} \cdot$ Bin Yang $^{1} \cdot$ Yu-Tao Xiang ${ }^{2}$ \\ Published online: 5 September 2020 \\ C Springer Science+Business Media, LLC, part of Springer Nature 2020
}

\begin{abstract}
Patients with severe mental illnesses (SMI) were at high risk of infection during Coronavirus Diseases 2019 (COVID-19) pandemic. This study examined hospitalized SMI patients' attitude and knowledge towards the COVID-19 infection. A cross-sectional survey was conducted in five psychiatric hospitals located in Gansu province, the most economically underdeveloped area in China. Patients' attitude towards preventive measures and knowledge of COVID-19 were measured by a self-report questionnaire. A total of 925 hospitalized patients with SMI were recruited. Of them, $84.8 \%$ (95\%CI: 82.4\%-87.1\%) had positive attitudes towards preventive measures of the COVID-19 outbreak. Being married (OR: 1.55, 95\%CI: 1.05-2.30) and a higher educational level (OR: 1.63, 95\%CI: 1.12-2.38) were independently associated with positive attitudes towards COVID-19 preventive measures, whereas higher educational level was associated with better knowledge of the COVID-19 outbreak ( $\beta$ : 0.231, $P<0.001)$. Patients mainly received COVID-19 relevant knowledge from public media (58.9\%), followed by their clinicians (33.2\%). Most hospitalized SMI patients in economically underdeveloped areas in China showed positive attitudes towards COVID-19 preventive measures. However, public health education on COVID-19 relevant knowledge by mental health professionals was inadequate to reduce the risk of transmission and infection.
\end{abstract}

Keywords Attitude $\cdot$ COVID-19· Severe mental illness $\cdot$ Economically underdeveloped

Ju-Hong Zhu and Wen Li contributed equally to this work.

Electronic supplementary material The online version of this article (https://doi.org/10.1007/s11126-02009835-1) contains supplementary material, which is available to authorized users.

Bin Yang 156892477@qq.com

Yu-Tao Xiang xyutly@gmail.com

Extended author information available on the last page of the article 


\section{Introduction}

The Coronavirus Diseases 2019 (abbreviated COVID-19) was first found in Wuhan, China in late December 2019, and COVID-19 became a pandemic in early March, 2020, as declared by the World Health Organization (WHO) [1]. As of April 16, 2020, COVID-19 has affected 185 countries and caused over 136 thousands deaths out of more than 2 million confirmed cases [2]. During the COVID19 pandemic, patients with severe mental illnesses (SMI) were also affected. Compared to the general population, SMI patients are even more vulnerable to be infected due to lowered sensitivity to threats and limited self-protection awareness of the infection [3]. In addition, they are less likely to comply with the preventive measures for the COVID-19, such as wearing facemasks, frequent hand-washing, self-quarantine, and social distancing. Furthermore, due to unhealthy lifestyle and medication-induced side effects, patients with SMI have a higher risk of physical comorbidities [4, 5], which could largely increase treatment difficulty if they contract a COVID-19 infection.

At an early stage of the COVID-19 outbreak, it was reported that hospitalized psychiatric patients and mental health professionals were infected with COVID-19 in some Asian countries [6,7], which suggested the high risk of cross infection in psychiatric hospitals. In China, psychiatric hospitals are usually over-crowded, patients typically share a common bathroom and dining areas, and receive group therapy in an overcrowded area, and all of these factors can increase the likelihood of rapid disease transmission. In addition, since most SMI inpatients are treated in closed wards, they have limited access to the internet, which may deter them to obtain COVID-19 relevant knowledge online. Consequently, hospitalized psychiatric patients were exposed to higher risk of infection. Furthermore, compared to general hospitals, psychiatric hospitals usually have less medical supplies, including personal protective equipment for infectious diseases [3,8]. Mental health professionals often have inadequate clinical experiences and skills in managing infectious diseases [9, 10].

In order to reduce infectious risk among patients with SMI, Chinese health authorities and relevant academic associations released several guidelines and consensus [10] during the COVID19 outbreak [11]. For instance, it is recommended that psychiatric hospitals should implement preventive measures towards COVID-19, e.g., isolation units should be established for newly admitted patients, family visits should be suspended, admission criteria should be tightened, and medical staff should receive regular training on prevention and management of infectious diseases $[3,8]$. Despite the development of these contingent guidelines and consensus, previous studies found that patients' adherence to preventive measures were crucial for prevention and control of infectious diseases in psychiatric hospitals. Whether patients adhere to these preventive measures were closely associated with their knowledge of and attitude towards the infectious disease [12].

To date, COVID-19 relevant knowledge and attitudes have been investigated among the general population [13] and medical professionals [9]. However, no relevant data were reported in psychiatric patients. Thus, this study examined hospitalized patients' attitude and knowledge towards COVID-19 in economically underdeveloped areas of China.

\section{Methods}

\section{Study Site and Participants}

This cross-sectional survey was conducted in five public psychiatric hospitals between February 28 and March 6, 2020 in Gansu province - the most economically underdeveloped 
province in China [14]. To be eligible, participants were: 1) hospitalized psychiatric patients aged between 18 and 59 years; 2) diagnosed with SMI, including schizophrenia and mood disorder (i.e., bipolar disorder or major depressive disorder) according to the International Statistical Classification of Diseases and Related Health Problems, 10th Revision (ICD-10) [15]. There were no exclusion criteria in this study. The study protocol was approved by the Institutional Review Board of Lanzhou University Second Hospital. All participants were required to provide written informed consent prior to participation in this study.

\section{Assessment}

Basic social-demographic and clinical characteristics were collected including gender, age, marital status, illness duration, and educational level. Patients' attitude towards preventive measures towards COVID-19 outbreak in hospitals was investigated by asking the following standardized question: "Do you think it is necessary to take preventive measures during your stay in the hospital?" (yes/no). Patients' knowledge of COVID-19 was evaluated by a questionnaire comprising ten "True/False" questions (Supplementary Table 1). Following previous studies [13], this questionnaire was derived according to the "Guidelines for Prevention of the Coronavirus Diseases 2019" which was released by the Bureau of Disease Control and Prevention of National Health Commission [16]. The scoring of this questionnaire was obtained by adding the number of correct answers to these ten questions, ranging from 0 to 10 . Higher scores indicated better knowledge towards COVID-19. In addition, patients were asked about the formal / informal sources to obtain the COVID-19 relevant information by a singlechoice question: "Where did you obtain relevant information on COVID-19?" (1: medical staff; 2: mass media or 3: others).

\section{Statistical Analyses}

Data analyses were performed using SPSS 24.0 for Windows (SPSS Inc., Chicago, IL, USA). Multiple logistic regression analysis was performed to identify factors which were independently associated with patients' attitude towards preventive measures of COVID-19 during hospitalization. Patients' attitude was the dependent variable, while demographic and clinical characteristics were entered as independent variables. Multiple linear regression analysis was performed to explore the independent associated factors of COVID-19's relevant knowledge. The total score of the knowledge on COVID-19 was the dependent variable, while demographic and clinical characteristics were entered as independent variables. The significance level was set as $P<0.05$ (two-tailed).

\section{Results}

A total of 1016 patients were recruited and 925 participated in this study. Patients' demographic and clinical characteristics are presented in Table 1.

\section{Patients' Attitude towards Preventive Measures of COVID-19 during Hospitalization}

Of the participants, $84.8 \%$ (95\% confidence interval (CI): $82.4 \%-87.1 \%$ ) had a positive attitude towards preventive measures of COVID-19. As presented in Table 1, multiple logistic 
Table 1 Social demographic and clinical characteristics independently associated with patients' attitude towards preventive measures of COVID-19

\begin{tabular}{|c|c|c|c|c|c|c|}
\hline \multirow[t]{2}{*}{ Variables } & & \multirow[t]{2}{*}{$\mathrm{N}$} & \multirow[t]{2}{*}{$\begin{array}{l}\text { Positive attitude } \\
(\%)\end{array}$} & \multicolumn{3}{|c|}{$\begin{array}{l}\text { Multiple logistic } \\
\text { regression analysis }\end{array}$} \\
\hline & & & & $P$ & OR & $95 \% \mathrm{CI}$ \\
\hline \multirow[t]{2}{*}{ Diagnosis } & Schizophrenia* & 657 & 83.6 & - & - & - \\
\hline & Mood disorder ${ }^{\#}$ & 268 & 87.7 & 0.330 & 1.24 & $0.80-1.92$ \\
\hline \multirow[t]{3}{*}{ Age (years) } & $<30^{*}$ & 280 & 87.5 & 0.311 & - & - \\
\hline & $30-40$ & 273 & 86.1 & 0.955 & 0.99 & $0.59-1.65$ \\
\hline & $>40$ & 372 & 81.7 & 0.216 & 0.73 & $0.44-1.21$ \\
\hline \multirow[t]{2}{*}{ Gender } & Female $^{*}$ & 309 & 87.4 & - & - & - \\
\hline & Male & 616 & 83.4 & 0.543 & 0.88 & $0.58-1.34$ \\
\hline \multirow[t]{2}{*}{ Marital status } & Unmarried* & 449 & 82.4 & - & - & - \\
\hline & Married & 476 & 87.0 & 0.028 & 1.55 & $1.05-2.30$ \\
\hline \multirow{3}{*}{$\begin{array}{l}\text { Illness duration } \\
\quad \text { (years) }\end{array}$} & $<1^{*}$ & 161 & 85.1 & 0.323 & - & - \\
\hline & $1-5$ & 289 & 88.2 & 0.312 & 1.34 & $0.76-2.37$ \\
\hline & $>5$ & 475 & 82.5 & 0.859 & 0.95 & $0.57-1.60$ \\
\hline \multirow[t]{2}{*}{ Educational level } & $\underset{*}{\text { Lower (primary school and below) }}$ & 315 & 80.0 & - & - & - \\
\hline & $\begin{array}{l}\text { Higher (secondary school and } \\
\text { above) }\end{array}$ & 610 & 87.2 & 0.012 & 1.63 & $1.12-2.38$ \\
\hline
\end{tabular}

* : Reference group; \# : including major depressive disorder and bipolar disorder; bolded value: $P<0.05$; Abbreviation: OR: odds ratio; CI: confidential interval

regression analysis revealed that being married (OR: $1.55,95 \% \mathrm{CI}: 1.05-2.30, P=0.028)$, and higher educational level (OR: $1.63,95 \% \mathrm{CI}: 1.12-2.38, P=0.012)$ were more likely to have positive attitude towards preventive measures of COVID-19.

\section{Patients' Knowledge of COVID-19}

The mean score of the relevant knowledge on COVID-19 was 7.63 (standard deviation (SD): 2.30). As presented in Table 2, multiple linear regression analysis revealed that greater COVID-19 relevant knowledge was positively associated with higher educational level (vs. lower educational level, $\beta$ : $0.231, P<0.001)$.

\section{Patients' Preferred Sources to Obtain Information about COVID-19}

Patients mainly obtained COVID-19 relevant knowledge from traditional public media $(58.9 \%)$, followed by information given by the medical staff $(33.2 \%)$ and other methods $(7.9 \%)$.

\section{Discussion}

To the best of our knowledge, this was the first study that examined the relevant attitude and knowledge among SMI patients towards COVID-19 globally. We found that most hospitalized patients with SMI $(84.8 \%, 95 \% \mathrm{CI}: 82.4 \%-87.1 \%)$ had a positive attitude towards COVID-19 
Table 2 Factors independently associated with the COVID-19 knowledge

\begin{tabular}{|c|c|c|c|c|c|}
\hline \multirow[t]{2}{*}{ Variables } & \multirow[t]{2}{*}{ Category } & \multirow[t]{2}{*}{ Knowledge score $(\mathrm{M} \pm \mathrm{SD})$} & \multicolumn{3}{|c|}{$\begin{array}{l}\text { Multiple linear regression } \\
\text { analysis }\end{array}$} \\
\hline & & & Coefficients & $\mathrm{t}$ & $P$ \\
\hline \multirow[t]{2}{*}{ Diagnosis } & Schizophrenia* & $7.57 \pm 2.35$ & & & \\
\hline & Mood disorder ${ }^{\#}$ & $7.78 \pm 2.16$ & 0.021 & 0.623 & 0.533 \\
\hline \multirow[t]{3}{*}{ Age (year) } & $<30^{*}$ & $7.93 \pm 2.17$ & & & \\
\hline & $30-40$ & $7.55 \pm 2.18$ & -0.045 & -1.143 & 0.253 \\
\hline & $>40$ & $7.46 \pm 2.46$ & -0.046 & -1.074 & 0.283 \\
\hline \multirow[t]{2}{*}{ Gender } & Female* & $7.92 \pm 2.25$ & - & - & - \\
\hline & Male & $7.49 \pm 2.31$ & -0.062 & -1.872 & 0.062 \\
\hline \multirow[t]{2}{*}{ Marital status } & Unmarried $^{*}$ & $7.57 \pm 2.32$ & - & - & - \\
\hline & Married & $7.69 \pm 2.28$ & 0.040 & 1.175 & 0.240 \\
\hline \multirow[t]{3}{*}{ Illness duration (year) } & $<1^{*}$ & $7.52 \pm 2.34$ & - & - & - \\
\hline & $1-5$ & $7.76 \pm 2.25$ & 0.058 & 1.308 & 0.191 \\
\hline & $>5$ & $7.59 \pm 2.32$ & 0.051 & 1.111 & 0.267 \\
\hline \multirow[t]{2}{*}{ Educational level } & $\begin{array}{l}\text { Lower (primary } \\
\quad \text { school and below) }\end{array}$ & $6.86 \pm 2.58$ & - & - & - \\
\hline & $\begin{array}{l}\text { Higher (secondary } \\
\text { school and above) }\end{array}$ & $8.03 \pm 2.04$ & 0.231 & 7.042 & $<0.001$ \\
\hline
\end{tabular}

* : Reference group; \# : including major depressive disorder and bipolar disorder; Bolded value: $P<0.05$; Abbreviation: M: mean; SD: standard deviation

preventive measures. The predominant positive attitude among SMI patients may be related to persistent education and efforts on the importance of COVID-19 preventive measures at national and regional levels since January 2020, which could increase patients' adherence to the preventive measures and reduce the risk of cross infection in psychiatric settings. In addition, SMI patients with good knowledge of COVID-19 could have better understanding of the importance of preventive measures to reduce the likelihood of contracting the infection. The results showed that SMI patients possessed satisfactory knowledge of COVID-19 (knowledge assessment score: $7.63 \pm 2.30$ out of 10 ).

Of particular note that nearly half of the hospitalized patients with SMI received COVID-19 relevant knowledge from public media (58.9\%). During the COVID-19 outbreak, relevant news was intensively shared, and public health education has been regularly delivered through traditional public media, such as television, radio and newspaper [17]. It was noteworthy that only one third of the inpatients in this study obtained COVID-19 relevant knowledge from psychiatrists or other mental health professionals, which indicates that public health education on COVID-19 needed to be addressed in psychiatric hospitals. In addition, results from a recent study found that only $64.6 \%$ of mental health professionals received relevant training in early stage of the COVID-19 outbreak in Chinese psychiatric hospitals [9]. As such, mental health professionals may not be equipped with sufficient knowledge to provide systematic education for psychiatric inpatients. More importantly, mental health professionals in economically underdeveloped areas of China were always insufficient / understaffed [18, 19]. During the COVID-19 outbreak, mental health professionals in psychiatric hospitals were required to provide extra mental health services to those affected by COVID-19, and provide online crisis psychological interventions. These mental health professionals may also be summoned and outsourced to join the external expert teams in Hubei province, China. Some 
psychiatrists may also be deployed to work in fever clinics. All these factors may inevitably delay or scale down essential mental health services / public health education in psychiatric hospitals.

As expected, patients with higher educational level were more knowledgeable about COVID-19 and more likely to have a positive attitude towards preventive measures than those with lower educational level. Our findings are consistent with other recent research findings in the Chinese general population [13]. The positive association between educational level and disease relevant knowledge has also been consistently reported in patients with other diseases, such as hypertension [20], gestational diabetes mellitus [21], and cardiovascular and cerebrovascular disease [22, 23]. Better educated patients are more likely to understand the importance of relevant knowledge in disease prevention and hence, they are more motivated to equip themselves with the essential knowledge in combating the COVID-19 outbreak. We also found that married patients were more likely to have positive attitude towards preventive measures of COVID-19. Being married is typically associated with better social support [24]. Patients' spouse may encourage patients to maintain healthy behaviours and lifestyle [25], and motivate them to adopt preventive measures during the infectious disease outbreak [25, 26].

The strengths of this study include the relatively large sample size and the multicentre design in most economically underdeveloped areas in China. However, several limitations should be addressed. First, due to logistical reasons, only hospitalized inpatients were included, which could limit the generalization of the results to community-dwelling patients. Second, some factors (e.g., illness severity) related to the COVID-19 relevant knowledge and attitude were not examined.

In conclusion, most hospitalized patients with SMI residing in economically underdeveloped areas in China showed positive attitudes towards COVID-19 preventive measures. However, further training and education on COVID-19 relevant knowledge should be delivered to mental health professionals, as they were the first point of contact for psychiatric patients to solicit important health information. As such, mental health professionals played a pivotal role in reducing the risk of transmission to this vulnerable subpopulation.

Acknowledgments The authors are grateful to all patients and clinicians involved in this study.

Availability of Data and Material Not applicable.

Authors' Contributions Study Design: Yu-Tao Xiang, Bin Yang. Data collection, analysis and interpretation of data: Ju-Hong Zhu, Wen Li, Xiao-Ning Huo, Hong-Min Jin, Chun-Hu Zhang, Jin-De Yun, Li-Guo Gao, Bin Yang, Yu-Tao Xiang. Drafting of the manuscript: Wen Li, Ju-Hong Zhu, Yu-Tao Xiang. Critical revision of the manuscript: Teris Cheung, Brian J. Hall. Approval of the final version for publication: All the authors.

\section{Compliance with Ethical Standards}

Conflict of Interest The authors declare that they have no conflicts of interest concerning this paper.

Research Involving Human Participants and/or Animals The study protocol was approved by the Institutional Review Board of Lanzhou University Second Hospital.

Informed Consent All participants provided written informed consent prior to participation in this study. 


\section{References}

1. WHO Director. WHO Director-General's opening remarks at the media briefing on COVID-19 - 11 March 2020. https://wwwwhoint/dg/speeches/detail/who-director-general-s-opening-remarks-at-the-mediabriefing-on-covid-19-11-march-2020 (access April 14, 2020)). 2020.

2. Johns Hopkins University. COVID-19 Dashboard by the Center for Systems Science and Engineering (CSSE) at Johns Hopkins University (JHU). https://coronavirusjhuedu/maphtml (access April 16, 2020)). 2020.

3. Zhu Y, Chen L, Ji H, Xi M, Fang Y, Li Y. The risk and prevention of novel coronavirus pneumonia infections among inpatients in psychiatric hospitals. Neurosci Bull. 2020;36:299-302. https://doi. org/10.1007/s12264-020-00476-9.

4. Penninx BWJH, Lange SMM. Metabolic syndrome in psychiatric patients: overview, mechanisms, and implications. Dialogues Clin Neurosci. 2018;20(1):63-73.

5. Ijaz S, Bolea B, Davies S, Savović J, Richards A, Sullivan S, et al. Antipsychotic polypharmacy and metabolic syndrome in schizophrenia: a review of systematic reviews. BMC Psychiatry. 2018;18(1):275. https://doi.org/10.1186/s12888-018-1848-y.

6. China News Weekly. About 80 doctors and patients at the Wuhan Mental Health Center were diagnosed with novel coronavirus pneumonia (in Chinese). http://societypeoplecomcn/n1/2020/0209/c100831577664html (access February 19th, 2020). 2020.

7. Shim E, Tariq A, Choi W, Lee Y, Chowell G. Transmission potential and severity of COVID-19 in South Korea. Int J Infect Dis. 2020;18(93):339-44. https://doi.org/10.1016/j.ijid.2020.03.031.

8. Xiang Y-T, Zhao Y-J, Liu Z-H, Li X-H, Zhao N, Cheung T, et al. The COVID-19 outbreak and psychiatric hospitals in China: managing challenges through mental health service reform. Int J Biol Sci. 2020;16(10): 1741-4. https://doi.org/10.7150/ijbs.45072.

9. Shi Y, Wang J, Yang Y, Wang Z, Wang G, Hashimoto K, et al. Knowledge and attitudes of medical staff in Chinese psychiatric hospitals regarding COVID-19. Brain Behav. Immunity - Health. 2020;4:100064. https://doi.org/10.1016/j.bbih.2020.100064.

10. Chinese Society of Psychiatry. Expert consensus on managing pathway and coping strategies for patients with mental disorders during prevention and control of infectious disease outbreak (Novel Coronavirus Pneumonia) (in Chinese). Chinese Society of Psychiatry, China: 2020.

11. Li W, Yang Y, Liu Z-H, Zhao Y-J, Zhang Q, Zhang L, et al. Progression of mental health services during the COVID-19 outbreak in China. Int J Biol Sci. 2020;16(10):1732-8. https://doi.org/10.7150/ijbs.45120. eCollection 2020.

12. Tachfouti N, Slama K, Berraho M, Nejjari C. The impact of knowledge and attitudes on adherence to tuberculosis treatment: a case-control study in a Moroccan region. Pan Afr Med J. 2012;12:52 PMCID: PMC3428172.

13. Zhong B-L, Luo W, Li H-M, Zhang Q-Q, Liu X-G, Li W-T, et al. Knowledge, attitudes, and practices towards COVID-19 among Chinese residents during the rapid rise period of the COVID-19 outbreak: a quick online cross-sectional survey. Int J Biol Sci. 2020;16(10):1745-52. https://doi.org/10.7150 /ijbs.45221.

14. Yang Q. The formulation and implementation of Gansu provincial government strategic management under the background of "one belt and one road" (in Chinese). Fujian Zhiliang Guanli. 2019;7:225.

15. World Health Organization. The ICD-10 classification of mental and behavioural disorders: clinical descriptions and diagnostic guidelines. Geneva: World Health Organization; 1992.

16. National Health Commission tBoDCaP. Guidelines for Public Prevention of the Novel CoronavirusInfected Pneumonia, the second edition (in Chinese). http://wwwchinacdccn/jkzt/crb/zl/szkb_11803/ jszl_2275/202001/t20200131_212080html (access April 11, 2020). 2020.

17. Xinhuanet. Television stations around the country should increase the report on the reprevention and control of the outbreak and reduce entertainment programmes (in Chinese). http://wwwxinhuanetcom/politics/ 2020-01/28/c 1125508200htm (access January 28, 2020). 2020.

18. Xiang YT, Yu X, Sartorius N, Ungvari GS, Chiu HF. Mental health in China: challenges and progress. Lancet (London, England). 2012;380(9855):1715-6. https://doi.org/10.1016/s0140-6736(11)60893-3.

19. Xiang Y-T, Ng CH, Yu X, Wang G. Rethinking progress and challenges of mental health care in China. World Psychiat. 2018;17(2):231-2. https://doi.org/10.1002/wps.20500.

20. Bacha D, Abera H. Knowledge, attitude and self-care practice towards control of hypertension among hypertensive patients on follow-up at St. Paul's hospital, Addis Ababa. Ethiop J Health Sci. 2019;29(4):42130. https://doi.org/10.4314/ejhs.v29i4.2.

21. Hussain Z, Yusoff ZM, Sulaiman SA. Evaluation of knowledge regarding gestational diabetes mellitus and its association with glycaemic level: a Malaysian study. Prim Care Diabetes. 2015;9(3):184-90. https://doi. org/10.1016/j.pcd.2014.07.007. 
22. Tawalbeh LI, Al Qadire M, Ahmad MM, Aloush S, Abu Sumaqa Y, Halabi M. Knowledge and self-care behaviors among patients with heart failure in Jordan. Res Nurs Health. 2017;40(4):350-9. https://doi. org/10.1002/nur.21805.

23. Faiz KW, Sundseth A, Thommessen B, Ronning OM. Patient knowledge on stroke risk factors, symptoms and treatment options. Vasc Health Risk Manag. 2018;14:37-40. https://doi.org/10.2147/vhrm.s152173.

24. Robles TF, Slatcher RB, Trombello JM, McGinn MM. Marital quality and health: a meta-analytic review. Psychol Bull. 2014;140(1):140-87. https://doi.org/10.1037/a0031859.

25. Wood R, Goesling B, Avellar S. The effects of marriage on health: a synthesis of recent research evidence. Washington, DC: Department of Health \& Human Services, Office of the Secretory; 2007.

26. Chen S-Y. Does marriage improve health? The evidence from CGSS2013 and CGSS2015 (in Chinese) East China Normal University; 2019.

Publisher's Note Springer Nature remains neutral with regard to jurisdictional claims in published maps and institutional affiliations.

Ju-Hong Zhu, MD, is a psychiatrist in Lanzhou University Second Hospital, Gansu province, China.

Wen Li, MD, is a PhD student in Faculty of Health Sciences, University of Macau, Macao SAR, China.

Xiao-Ning Huo, MD, is a psychiatrist in the Third People's Hospital of Lanzhou, Gansu province, China.

Hong-Min Jin , MD, is a psychiatrist in Baiyin Mental Health Center, Gansu province, China.

Chun-Hu Zhang, MD, is a psychiatrist in the Fourth People's Hospital of Pingliang, Gansu province, China.

Jin-De Yun , MD, is a psychiatrist in the Second People's Hospital of Anding District, Dingxi city, Gansu province, China.

Li-Guo Gao, MD, is a psychiatrist in Red Cross Psychiatric Hospital of Zhangye, Gansu Province, China.

Teris Cheung, $\mathrm{PhD}$, is a research assistant professor in Hong Kong Polytechnic University, Hong Kong SAR, China.

Brian J. Hall , PhD, is a professor of Global Public Health at NYU Shanghai, Shanghai, China.

Bin Yang, MD, is a psychiatrist in Lanzhou University Second Hospital, Gansu province, China.

Yu-Tao Xiang, MD, PhD, is a professor in University of Macau, Macao SAR, China. 


\section{Affiliations}

Ju-Hong Zhu ${ }^{1} \cdot$ Wen $\mathrm{Li}^{2} \cdot$ Xiao-Ning Huo ${ }^{3} \cdot$ Hong-Min Jin ${ }^{4} \cdot$ Chun-Hu Zhang ${ }^{5} \cdot \mathrm{Jin}-\mathrm{De}$

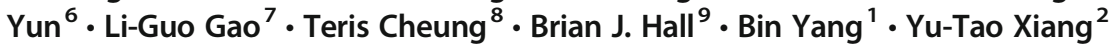

1 Department of Psychiatry, Lanzhou University Second Hospital, Lanzhou, Gansu province, China

2 Center for Cognition and Brain Sciences, University of Macau, Macao SAR, China

3 The Third People's Hospital of Lanzhou, Lanzhou, Gansu province, China

4 Baiyin Mental Health Center, Baiyin, Gansu province, China

5 The Fourth People's Hospital of Pingliang, Pingliang, Gansu province, China

6 The Second People's Hospital of Anding District, Dingxi city, Gansu province, China

7 Red Cross Psychiatric Hospital of Zhangye, Zhangye, Gansu Province, China

8 School of Nursing, Hong Kong Polytechnic University, Kowloon, Hong Kong SAR, China

9 Global and Community Mental Health Research Group, New York University (Shanghai), Shanghai, China 